
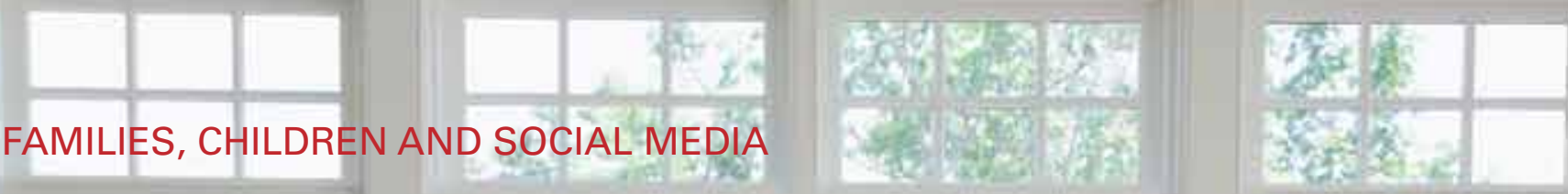

FAMILIES, CHILDREN AND SOCIAL MEDIA
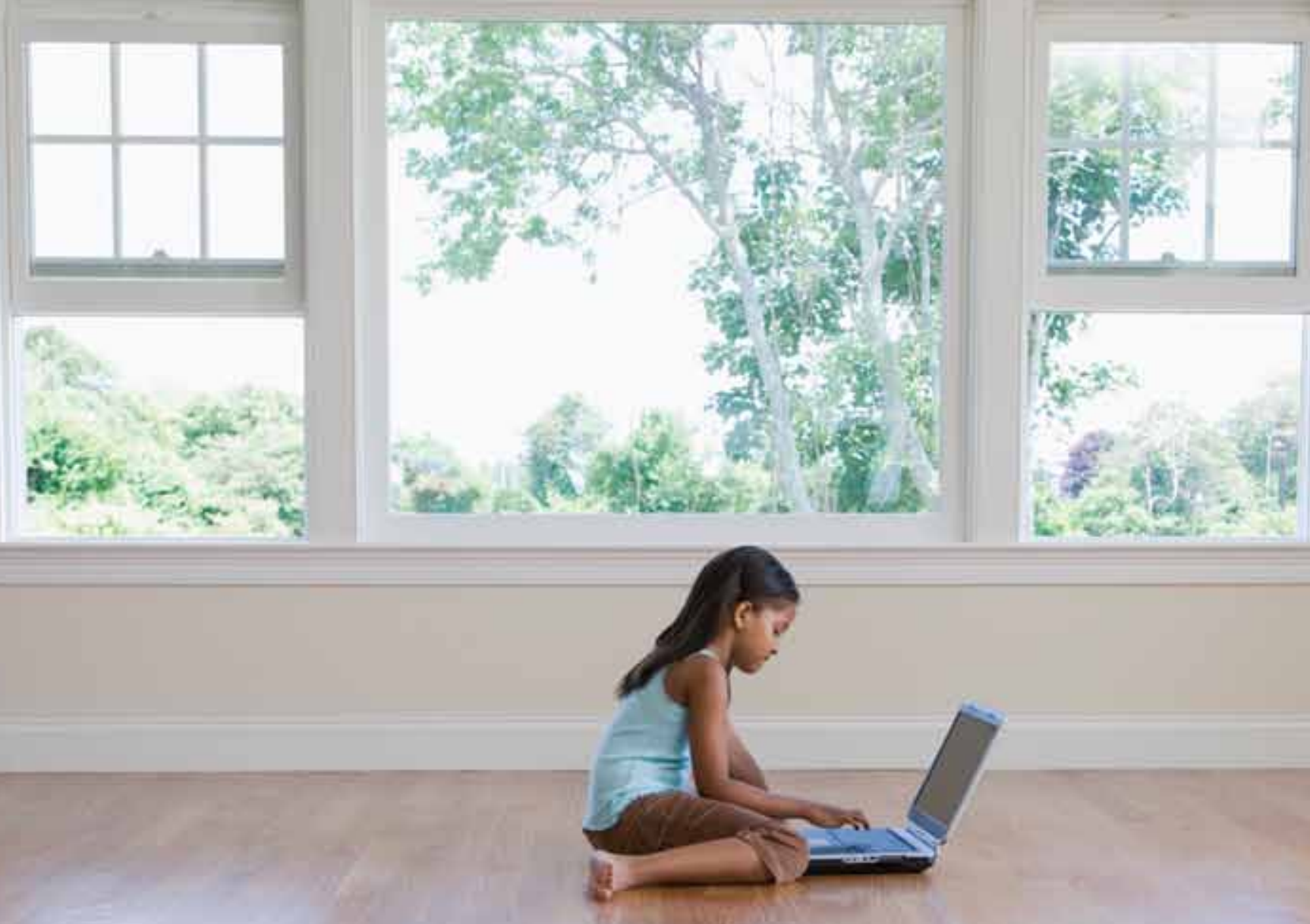

\title{
Social Media and
}

the Medical Industry:

A Whole New Sort of Healthcare Network

Observations on healthcare and social media from a marketer

Max Valiquette 


\section{Consumers of media are now creators of media, and we can all shout whatever we want, to whomever we want, whenever we want.}

$\mathrm{F}$ irst things first: I'm not a doctor, or any sort of healthcare professional (but do keep reading, anyway). I'm a marketer - I know! - and even more gallingly, I'm a social media consultant, which is actually a thing now. I exist. Broadly speaking, what I do is called strategic planning, in that I help organizations solve their problems through a greater understanding of their users, and I've focused on the youth market for most of my career. This has meant that I've had to also focus on social networks and social media - a whole channel of communication that has essentially been invented by young people. So to better understand social media and healthcare, we first have to understand social media, period.

The ad agency I work for, Bensimon Byrne, publishes a report called Consumerology (you can read it at consumerology. ca) every few months in which we survey a minimum of 1,200 Canadians about a range of subjects. The most recent survey was about social networks, and our findings confirm a couple of things: young people are more active in these networks, and young people set trends that older generations follow. This is the data's way of saying that the way young people act in social media is relevant not only if you have to deal with young clients but also because this generation increasingly sets trends that adults follow. We believe, and the data support this, that social media is an "and-the-youth-shall-lead-them" sort of thing.

You're still reading (hooray!), but you're also probably wondering what the relevance of all this is to you. It's simply this: social networks and social media are transforming absolutely every single industry, and medicine is no different. And the younger your patients are, the more this matters. For those of you treating young people, you've essentially got two clients for whom social media is huge: the older kids whom you're treating and the parents of the younger ones. Medical professionals dealing with tween and teen patients, as well as young parents of infants and kids, need to know whatever they can about social media.

So, here's a tiny history lesson: the single biggest development in digital culture in the past decade or so has been the development and proliferation of social networks. Broadly speaking, an online social network is a dedicated web-based service that allows a person to construct a profile and connect with others who have done so as well. In the beginning, through networks such as Friendster and MySpace, these were almost like an online dating profile that could be shared with everyone. And these were used almost exclusively by young people.

You've seen the movie The Social Network, so you know what happened next (and, if not, you probably feel like you saw the movie anyway): Facebook changed everything. Also initially youth focused (available only to students, even), it's now being used by people of all ages (but still most used by younger people). About 900 million people worldwide are on Facebook - it would be the third-largest country in the world now were it a nation - and it's become embedded into the fabric of our lives. Almost 20 million Canadians are on Facebook - more than the number of us who voted in our last federal election.

\section{It's Not Just Facebook}

We've also seen other social networks follow in Facebook's wake. The most important of these is Twitter. It follows the same basic format - start a page, connect to people and start a network, and engage with that network to share things or exchange information - but it works in "tweets," bursts of 140 characters in length at a time. So it's even faster and facilitates even more sharing. There's foursquare, a mobile-based network in which users "check in" to locations to alert people to where they are; Instagram, a photosharing based mobile network; and lots of others. Increasingly, these networks aren't just accessible via a laptop or desktop computer - they all have mobile versions, meaning that we quite literally take our networks with us wherever we go. This has led to more and more people signing on to mobile social: millions of Canadians are on Twitter (often through their smartphones); and foursquare and Instagram, which are only available in mobile, more than tripled in size in the past year.

So there's our history lesson - if we can refer to the past decade as history, really - and now it's time to think about what this means for you.

\section{The Social Media Revolution Is Not the First Digital Revolution in Healthcare}

Let's start by clarifying something: social media is not the first great revolution that the Internet has brought to the medical industry. It's the second or third. Prior to social media, your patients already had access to WebMD and (shudder) Wikipedia and other online sources for self-diagnosis (which, I'm guessing, makes your jobs more difficult, not less so). They also were able to read reviews of you and your colleagues at sites like RateMyMD.ca. But, up to that point, the change had involved an instantaneous connection to news sources and reference materials and websites that were created by others. This revolution is different - it's about giving people access to everyone they know whenever they want it, and also about giving them the ability to broadcast to that network whenever they see fit. Consumers of media are now 
Social Media Resources for Engagement in the Healthcare Sector

Interested in learning more about how social media is being used in healthcare? See below for some excellent examples of blogs, twitter feeds and web-based resources.

\section{Blogs}

Canadian Living Health \& Wellness Blog: http://www. canadianliving.com/blogs/health/

- CTV Health Blog: http://healthblog.ctv.ca/

- Weighty Matters Blog: http://www.weightymatters.ca/

-The Dr. Oz Blog: http://www.doctoroz.com/blogs

-The OMA President's Blog: https://www.oma.org/

Mediaroom/PM/Pages/default.aspx

-The Health Care Blog: http://thehealthcareblog.com/

- Well - NYTimes Health Blog: http://well.blogs.nytimes. com/

\section{Twitter Feeds}

- @ Mashable: http://twitter.com/\#!/mashable

@ MarkRaganCEO: http://twitter.com/\#!/markraganceo

- @ PicardonHealth: https://twitter.com/\#!/picardonhealth

- @SanjayGuptaCNN: https://twitter.com/\#!/sanjayguptacnn

- @CTV_AvisFavaro: http://twitter.com/\#!/ctv_avisfavaro

- @ChildrensBoston: http://twitter.com/\#!/childrensboston

- @ SunnybrookHSC: http://twitter.com/\#!/sunnybrookhsc

- @ LeeAase: http://twitter.com/\#!/leeaase

- @MayoClinic: http://twitter.com/\#!/mayoclinic

- @ JohnSharp: http://twitter.com/\#!/johnsharp

- @ClevelandClinic: http://twitter.com/\#!/clevelandclinic

- @ HospitalGroup: http://twitter.com/\#!/hospitalgroup

- @EdBennett: http://twitter.com/\#!/edbennett

- @UMMC: http://twitter.com/\#!/UMMC

- @Colleen_Young: http://twitter.com/\#!/colleen_young

- @ HCSMCA: http://twitter.com/\#!/hcsmca

- @SickKidsNews: http://twitter.com/\#!/sickkidsnews

- @ HEALTHCANADA: http://twitter.com/\#!/

HEALTHCANADA

- @ Deb_Matthews: http://twitter.com/\#!/deb_matthews

- @ Leonaaglukkaq: http://twitter.com/\#!/leonaaglukkaq

\section{Websites and Other Resources}

-The Mashable Twitter Guidebook: http://mashable.com/ guidebook/twitter/

- Parent Central (ofThe Toronto Star): http://www.parentcentral.ca/

- AboutKidsHealth: http://www.aboutkidshealth.ca/En/

Pages/default.aspx

-Today's Parent: http://www.todaysparent.com/

With thanks to the Public Affairs Department at The Hospital for Sick Children creators of media, and we can all shout whatever we want, to whomever we want, whenever we want. That represents a huge change - I would argue the biggest change we've seen in the history of media. We are all broadcasters now, and we've all got access to everyone we know whenever we want it. Every industry is being transformed - not just medicine. But this is a part of a larger process that has gradually taken a lot of the things that we used to keep off-line and moved them online. You probably accept that your patients are going to attempt a self-diagnosis through the Internet before they come and see you; now you have to accept a few other realities of the new social world.

\section{The Rise of the Digital Native}

Remember, this is a trend driven by young people; those 35 and under represent over half of Facebook users. Young people are early adopters of social networks, and their uptake is often what starts the ball rolling with those of other ages. At the same time, what we call "digital natives" - those young people who have essentially had the Internet for their whole lives - have a fundamentally different relationship with being online. And the older you are, or the more venerable your industry, or the longer a period of time your particular part of the medical field has been around, well, the harder it can be to change. So to understand the field of social media, try to think like a young person. If you've got younger people working with you, don't be afraid to pick their brains or even let them have a say in how the social media of your organization is managed. As scary as this may sound to some of you, it's the best way to do this.

\section{The YoungerYour Patients, the More They Share}

This is the fundamental truth of social media: the single biggest difference between "digital natives" and "digital tourists" - those who grew up and then got wired - is that the natives share pretty much everything. The Internet isn't just a tool for information and communication; it's about sharing - really personal sharing. And that fundamental need to share is transforming everything, including healthcare. If you've got kids of your own, you're probably already aware of this. (You may have had to pry a mobile device from their hands or deal with the fallout from some sort of status-updating-related overshare.) The reality of dealing with younger people in any industry is that one has to be prepared for how much they are going to share. In healthcare, this refers to how much they are going to automatically broadcast about where they are going, what they are feeling what's happened to them. I've found out that friends are at the hospital because they've "checked in" to one (meaning they've alerted their mobile social network as to their location). It may seem trivial, but this sort of reflexive sharing is having a massive impact on privacy. As well, we sometimes share too much when we're upset or when we've received difficult news. This had different consequences when we could only communicate with one person at a time. But imagine 
getting a tough piece of news from a doctor and automatically tweeting about it. People are doing this, and it means that we may need to change the sort of advice we're giving younger patients about what it means to broadcast their medical condition.

\section{Your Network Is Always with You}

There is a great likelihood that when you started working, hospitals were essentially self-contained organisms. Patients and their families would arrive and, once those doors shut, they pretty much left the outside world behind. Your teenage patients and - more importantly - the parents of your younger patients don't arrive in your waiting room alone anymore: they bring their network with them. And that means, on average, a network of close to 200 Facebook friends, or dozens and dozens of followers on Twitter, and often both of those. Earlier this year, a friend of mine had to wait a particularly long time to see her doctor - and this drove her nuts. So she told people about it. That may not sound so odd, except for a couple of things: one, she was able to tell everyone she knew about this simply by updating her Facebook status; and, two, she did this while she was still in the process of waiting. There is no gap between something happening and one's entire network finding out about it, even in medicine.

This matters more with every passing day as people learn to better use these networks to get what they want out of them. For patients, that's going to mean everything from referrals and recommendations about the right healthcare practitioner, to support and even updating. It is incredibly common now for people to update their entire network with big medical announcements - a baby is born, someone is out of the hospital - and paying attention to this reality is going to be an increasingly large part of how we practise medicine. If you're good at your job, one of your patients has already linked to you online on Facebook as a way of telling his or her network about you. Come to think of it, though, if your patients think you're bad at your job, they've probably done the same thing too.

\section{Communication Happens Online, as Do Empowerment and Lawsuits}

You're also going to be expected to communicate with your patients in these social arenas. It's not just that they are going to be looking for you to tweet about your field of practice; this is going to table stakes in the near future, in that you won't be considered legitimate without having some sort of social media presence. It's also where your patients are going to expect to be empowered about the medical issues that they have to deal with. There are lots of Facebook groups with titles such as "Preemie Parents" and "Breast Cancer Awareness" and everything else. This is where your patients want to go for communication, to get support from a larger group of people who understand their situation and even to learn about ways to cope. Knowing that level of communication, and empowerment, exists online is important in delivering a standard of care for your patients. And there's more: patients and doctors are live-tweeting events as they occur, and sometimes even going too far. Doctors (in the United States, not surprisingly) have already been sued for compromising the standard of care by revealing too much about particular patients online. This is going to be an especially tough line to balance: as patients expect - even demand - more to exist in social channels, medical professionals are going to have to communicate and connect with their patients in social media, but they must be certain to be cautious and not go too far.

\section{One Last Thing: Manage Your Own Privacy as Well}

This level of connection and sharing can also have consequences not only for patients but for practitioners as well. Understanding how privacy is changing is also understanding that it's a two-way street: you may have patients who are looking for you in social networks, and if you value your own privacy - or simply want to transfer whatever boundaries you've created in real life into your social networks - you'll want to manage your social media privacy settings. If you don't want people to be able to see your non-professional life, you have to make absolutely certain you manage that. This has actually been pretty significant in other industries - notably education - in which more than one teacher has had to deal with the professional fallout from students or parents discovering photos that were thought of as being less than professional. And it's not necessarily anything overly salacious or illegal - we're talking photos of alcohol consumption and the like. Ifyou don't want to be explaining to your patients about your personal life, make certain that they can't see it online. Some - not all, but some - will look for you with purpose, and some even just out of curiosity. If you don't want them to have access to your life, then don't give it.

So, as managing young patients and young parents means understanding their lives, it therefore means having some experience in social media. Get on Facebook, and Twitter, and foursquare and Instagram and anywhere else you think might be useful, and start by observing. Search within the networks of your choosing for the most famous people in your field, and see what they do. Find out what your hospital uses as social media guidelines. Enter your particular field of practice as a search term, and see what's happening. You don't have to start a Facebook page right away or start tweeting back and forth with your patients; you can just see what others are doing, and then slowly start to do your own thing. But social networks aren't going anywhere, so it's critical that the entire medical field learns to adapt to this new reality. Your patients are changing, and patient care should too. HQ

\section{About the Author}

Max Valiquette is the managing director of strategy at Bensimon Byrne, a Toronto-based advertising agency. 